\title{
Estrogen formulations and beauty care practices in Japanese women
}

This article was published in the following Dove Press journal:

International Journal of Women's Health

27 January 2012

Number of times this article has been viewed

\section{Takashi Takeda \\ Tze Fang Wong \\ Mari Kitamura \\ Nobuo Yaegashi}

Department of Obstetrics and Gynecology, Tohoku University

Graduate School of Medicine,

Miyagi, Japan
Correspondence: Takashi Takeda

Department of Obstetrics and

Gynecology, Tohoku University Graduate

School of Medicine, Seiryomachi I-I,

Aoba-ku, Sendai 980-8574, Miyagi, Japan

Tel +8I $227 \mid 77254$

Fax +8I 227177258

Email take@med.tohoku.ac.jp
Purpose: Traditionally, oral estrogens have been used for hormone replacement therapy. However, in Japan, additional estrogen formulations have been used, including transdermal patches and transdermal gels. The latter have a unique commonality with cosmetics because both of them are applied to the skin. Beauty care is one of the most important lifestyle factors for women, and it has been reported that the amount of attention paid to beauty care has an effect in determining whether or not women will choose to undergo HRT during menopause. Therefore, our study focused on estrogen formulations and beauty care practices.

Patients and methods: Fifty women who use hormone replacement therapy were recruited from the outpatient clinic of Tohoku University Hospital. They were treated with oral conjugated estrogen $(n=11)$, transdermal $17 \beta$-estradiol patch $(n=11)$, and transdermal $17 \beta$-estradiol gel $(\mathrm{n}=28)$. They completed a questionnaire to assess their lifestyle (beauty care practices and exercise habits) and their compliance. The transdermal gel users were further interviewed about their subjective impressions regarding "smell", "sticky feeling", "spreadability", and "irritation" on the skin using a five-grade scale.

Results: There were no differences in the usability of medicines and patient compliance among the estrogen formulations. We observed a positive tendency between the level of beauty care and transdermal gel use ( $P=0.0645$, ordinary logistic regression analysis). The gel users placed top priority on a lack of "sticky feeling" but the subjective impression regarding "sticky feeling" was worst among the four factors $(P<0.01$, Steel-Dwass test). Correspondence analysis showed that the subjective impressions of transdermal gel corresponding to usability in the range of "moderate" to "very good" and "sticky feeling" greatly affected the usability of the formulation.

Conclusion: These results suggest that the level of attention to beauty care plays some role in the choice of estrogen formulations.

Keywords: HRT, estrogen, transdermal gel, cosmetics, subjective impression

\section{Introduction}

Hormone replacement therapy (HRT) has been widely used for the control of vasomotor symptoms of post- and perimenopausal women. ${ }^{1,2}$ HRT is also employed for the treatment of premature ovarian failure (POF). ${ }^{3}$ Women with untreated premature ovarian failure are at increased risk of osteoporosis, cardiovascular disease, and dementia, among others. The common types of estrogen for estrogen therapy are conjugated equine estrogen and 17- $\beta$-estradiol. There are no data to suggest that any one formulation is clinically superior to another. ${ }^{4}$ Traditionally, oral estrogens have been used for estrogen therapy, but they have several disadvantages such as variable bioavailability and hepatic first-pass metabolism. To circumvent the side effects of 
the oral route, approaches using the transdermal route have been developed. ${ }^{5}$ Transdermal formulations, such as transdermal patches and transdermal gels, are available in Japan. Transdermal gels have a unique commonality with cosmetics because both of them are applied on the skin.

Beauty care is one of the most important lifestyle factors for women. It has been previously reported that the amount of attention paid to beauty care plays a role in determining HRT during menopause. ${ }^{6}$ Women tend to expect anti-aging effects such as maintaining a youthful appearance, improving skin tone, and preventing wrinkles to accompany HRT use. ${ }^{7}$ However, there have been no reports about the type of estrogen formulations and beauty care practices. In this study, we have investigated the relationship between estrogen formulations and beauty care practices and studied the usability of transdermal gel according to its cosmetic aspects.

\section{Material and methods}

The study was carried out in accordance with the principles outlined in the Declaration of Helsinki. ${ }^{8}$ Our institutional review board at Tohoku University approved the study (2010-390).

\section{Study population}

A cross-sectional study was conducted from November to December 2010. Fifty women, aged 22-58 years, who use HRT were recruited from the gynecologic outpatient clinic of Tohoku University Hospital in Sendai, Japan. They were all diagnosed with loss of ovarian function. They provided informed consent and could complete a questionnaire by themselves. They had used the same type of estrogen formula for at least 2 months.

\section{Questionnaire}

The questionnaire consisted of four parts. The first part included general profile factors such as age, occupation, time from the initiation of treatment to screening, type of estrogen (oral tablet, transdermal patch, or transdermal gel), and medical application. According participants' answers to this part, we divided the subjects into three groups: group 1, oral-conjugated estrogen (Premarin ${ }^{\circledR}$; Pfizer, Tokyo, Japan) $0.625 \mathrm{mg} /$ day $(\mathrm{n}=11)$, group 2 , transdermal $17 \beta$-estradiol patch (Estrana ${ }^{\circledR}$; Hisamitsu, Tokyo, Japan) $0.72 \mathrm{mg} / 2$ days $(\mathrm{n}=11)$, and group 3, transdermal 17 $\beta$-estradiol gel (Devigel ${ }^{\circledR}$; Motida, Tokyo, Japan) $1 \mathrm{mg} /$ day $(\mathrm{n}=28)$. The second part addressed usability and compliance. We asked, "What is the usability of your estrogen formula?" with the possible responses of "favorable", "rather favorable", "neutral", "rather unfavorable", or "unfavorable". We also asked, "How often do you forget your medication per month?" with the possible responses of "never", "once", "twice", "three times", or "more than three times". The third part included questions about lifestyle (beauty care practices and exercise habits) with four grades. As to the beauty care practices, we asked, "How often do you put on makeup?" with the possible responses of "every day", "sometimes", "rarely", or "never". As to their exercise habits, we asked, "How often do you engage in mild exercise?" with the possible responses of "once a week", “once a month", "once per 3 months", or "never". The transdermal gel users were further interviewed in the fourth part of the questionnaire. We asked about their priority regarding "smell", "sticky feeling", "spreadability", and "irritation" on the skin using a four-grade scale. Subjective impressions regarding these factors were also gathered using a five-grade scale.

\section{Analysis}

The significance of differences was evaluated by Chi-square test, Kruskal-Wallis test, or Steel-Dwass test. Statistical analysis was performed using Excel (2010; Microsoft Corporation, Redmond, WA) with the add-in software Statcel 3 (OMS, Tokyo, Japan), and SAS (v 9.1.3; SAS Institute Inc, NC, US). Statistical significance was set at $P<0.05$.

\section{Results \\ General profile}

We began by analyzing the questionnaire results for part 1. Demographic and clinical characteristics are shown in Table 1. The tablet group was younger than the gel group $(P<0.05)$. There were no differences between the groups with regards to occupation, time from the initiation of treatment, and medical application $(P>0.05)$.

\section{Usability and compliance}

The questionnaire results for part 2 are shown in Table 2. There were no differences between the groups with regard to usability and compliance $(P>0.05)$.

\section{Beauty care practices and exercise habits}

Next we analyzed the questionnaire results for part 3 (Table 3). There were no differences between the groups with regard to beauty care practices and exercise habits $(P>0.05)$. We further divided the subjects into three groups according to the frequency of beauty care practices and exercise habits (Figure 1). There were no differences 
Table I Demographic and clinical characteristics

\begin{tabular}{|c|c|c|c|}
\hline & $\begin{array}{l}\text { Group I } \\
\text { (tablet) } \\
\mathbf{n}=I I\end{array}$ & $\begin{array}{l}\text { Group } 2 \\
\text { (patch) } \\
n=I I\end{array}$ & $\begin{array}{l}\text { Group } 3 \\
\text { (gel) } \\
\mathbf{n}=\mathbf{2 8}\end{array}$ \\
\hline Age (years) mean (SE) & $34.5(3.34)^{*}$ & $44.2(2.45)$ & $43.1(1.63)$ \\
\hline \multicolumn{4}{|l|}{ Occupation } \\
\hline Business worker & 6 & 2 & 7 \\
\hline Individual proprietor & 0 & 0 & I \\
\hline Part-time worker & 2 & 5 & 6 \\
\hline Housewife & 1 & 3 & 12 \\
\hline Unemployed & 1 & I & 2 \\
\hline Others & I & 0 & 0 \\
\hline \multicolumn{4}{|l|}{$P=0.263$ (by Chi-square test) } \\
\hline \multirow{2}{*}{\multicolumn{4}{|c|}{$\begin{array}{l}\text { Time from initiation } \\
\text { of treatment (months) }\end{array}$}} \\
\hline & & & \\
\hline$<3$ & 1 & 2 & 5 \\
\hline $3-6$ & 2 & 3 & 6 \\
\hline $6-12$ & 2 & 0 & 8 \\
\hline$>12$ & 6 & 6 & 9 \\
\hline \multicolumn{4}{|l|}{$P=0.499$ (by Chi-square test) } \\
\hline \multicolumn{4}{|l|}{ Medical application } \\
\hline Climacteric disorder & I & 2 & 12 \\
\hline $\begin{array}{l}\text { Surgically or drug-induced } \\
\text { menopause }\end{array}$ & 4 & 4 & 8 \\
\hline Premature ovarian failure & 6 & 5 & 8 \\
\hline$P=0.240$ (by Chi-square test) & & & \\
\hline
\end{tabular}

Note: $* P<0.05$ vs gel (by one-way ANOVA followed by Scheffe's F-test).

between the groups with regard to age. According to the ordinary logistic regression analysis, we could detect a positive tendency, although it was not statistically significant, between the level of beauty care practices and transdermal gel use $(P=0.0645)$.

Table 2 Usability and compliance

\begin{tabular}{|c|c|c|c|}
\hline & $\begin{array}{l}\text { Group I } \\
\text { (tablet) } \\
\mathbf{n}=\mathrm{I} \text { I }\end{array}$ & $\begin{array}{l}\text { Group } 2 \\
\text { (patch) } \\
n=I \mid\end{array}$ & $\begin{array}{l}\text { Group } 3 \\
\text { (gel) } \\
n=28\end{array}$ \\
\hline \multicolumn{4}{|c|}{ Usability: "What is the usability } \\
\hline \multicolumn{4}{|l|}{ of your estrogen formula?" } \\
\hline "Favorable" & 2 & 5 & 4 \\
\hline "Rather favorable" & 3 & 2 & II \\
\hline "Neutral” & 6 & 4 & 10 \\
\hline "Rather unfavorable" & 0 & 0 & 3 \\
\hline “Unfavorable" & 0 & 0 & 0 \\
\hline \multicolumn{4}{|c|}{$P=0.312$ (by Kruskal-Wallis test) } \\
\hline \multicolumn{4}{|l|}{$\begin{array}{l}\text { Compliance: "How often do } \\
\text { you forget your medication }\end{array}$} \\
\hline “Never" & 5 & 8 & 13 \\
\hline “Once” & 4 & I & 8 \\
\hline "Twice" & I & 1 & 4 \\
\hline "Three times" & 0 & 0 & 3 \\
\hline "More than three times" & I & I & 0 \\
\hline$P=0.478$ (by Kruskal-Wallis & & & \\
\hline
\end{tabular}

Table 3 Beauty care practices and exercise habits

\begin{tabular}{|c|c|c|c|}
\hline & $\begin{array}{l}\text { Group I } \\
\text { (tablet) } \\
n=I I\end{array}$ & $\begin{array}{l}\text { Group } 2 \\
\text { (patch) } \\
n=I I\end{array}$ & $\begin{array}{l}\text { Group } 3 \\
\text { (gel) } \\
\mathbf{n = 2 8}\end{array}$ \\
\hline \multicolumn{4}{|l|}{ Beauty care practices: "How often } \\
\hline \multicolumn{4}{|l|}{ do you put on makeup?" } \\
\hline "Every day" & 4 & 3 & 18 \\
\hline "Sometimes" & 4 & 0 & 7 \\
\hline "Rarely" & I & 0 & I \\
\hline "Never" & 2 & 2 & 2 \\
\hline \multicolumn{4}{|l|}{$P=0.253$ (by Kruskal-Wallis test) } \\
\hline \multicolumn{4}{|l|}{$\begin{array}{l}\text { Exercise habits: "How often do you } \\
\text { engage in mild exercise?" }\end{array}$} \\
\hline "Once a week" & 4 & 4 & 16 \\
\hline "Once a month" & 0 & 2 & I \\
\hline "Once per three months" & 0 & 0 & 0 \\
\hline "Never" & 7 & 5 & II \\
\hline$P=0.394$ (by Kruskal-Wallis test) & & & \\
\hline
\end{tabular}

\section{Priority and usability for transdermal gel users}

We further analyzed the questionnaire results for part 4 (Figure 2). Transdermal gel users gave the highest priorities for lack of "sticky feeling" and lack of "irritation". As to the subjective impression of gel usability, "sticky feeling" had the lowest rating.

\section{Correspondence analysis of the subjective impression and the usability of transdermal gel}

Next we analyzed the relationship between the subjective impression of gel usability and the usability of gel. Correspondence analysis graphically showed that the subjective impressions of transdermal gel corresponding to usability in the range of "moderate" to "very good" and "sticky feeling" greatly affected the usability of the formulations (Figure 3).

\section{Discussion}

This is the first report about the relationship between estrogen formulations and beauty care practices; we also studied the usability of the transdermal gel according to its cosmetic aspects.

Transdermal estrogen administration bypasses first-pass metabolism and offers some advantages over oral administration. ${ }^{5}$ In view of these advantages, we recommend the administration of transdermal formulations (patch or gel) for all HRT users in our clinic. This would explain the high percentage of transdermal administration. However, there are some disadvantages, such as skin 


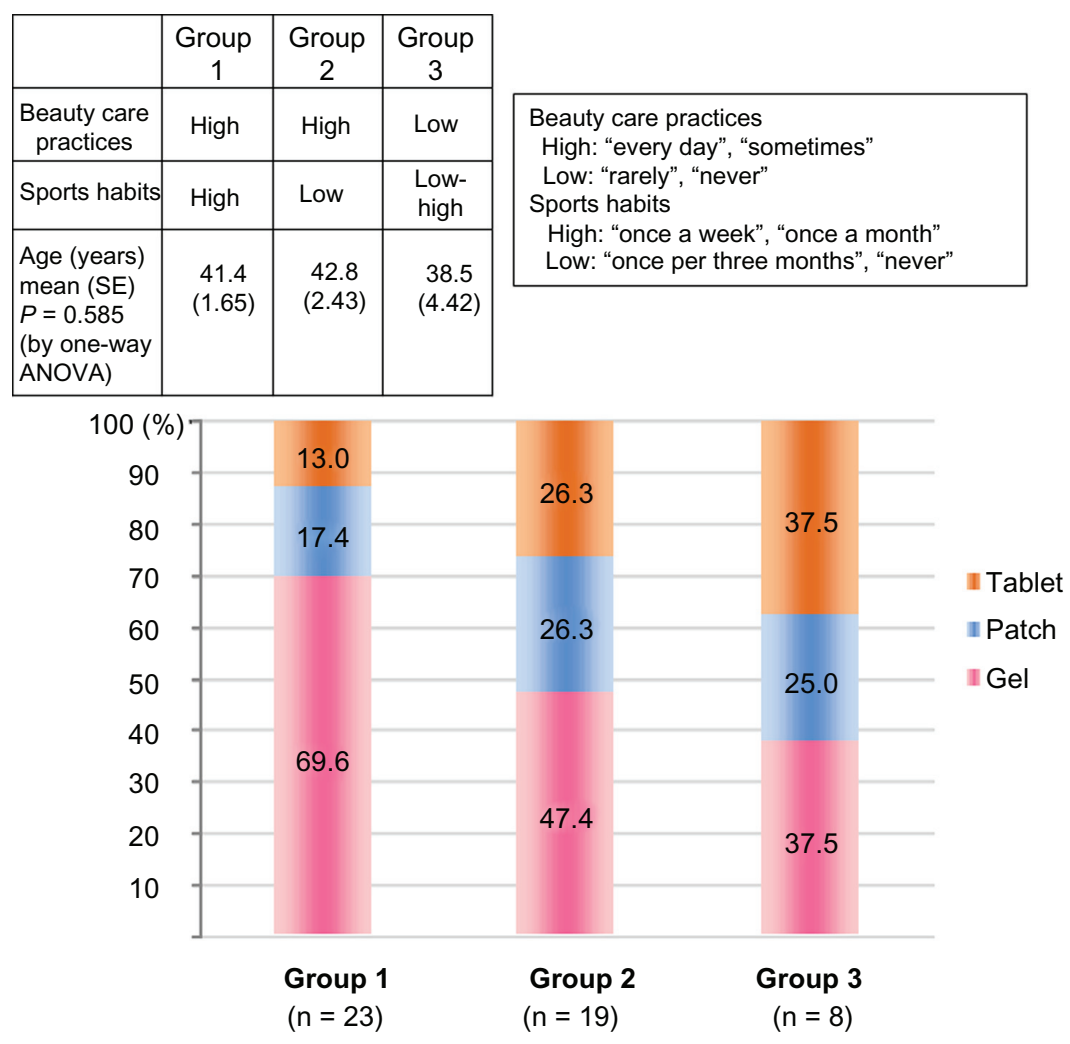

Figure I Relationship between the level of beauty care and choice of estrogen formulations. Note: $P=0.0645$, ordinary logistic regression analysis.

A

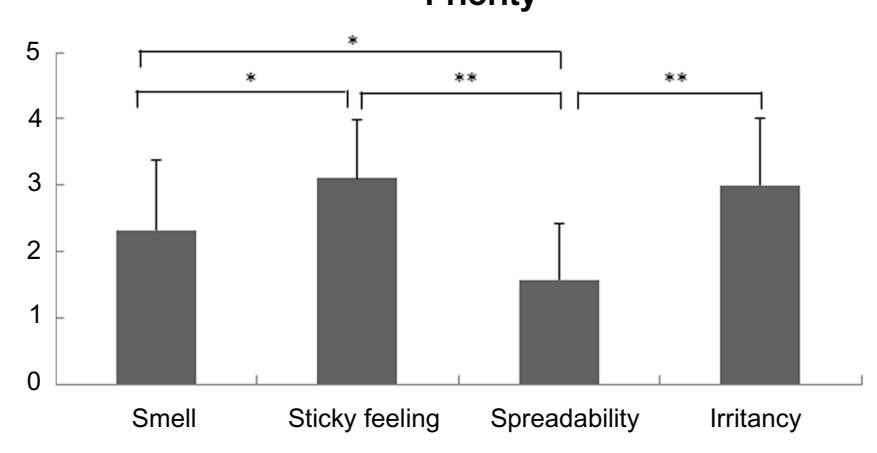

Subjective impression

B

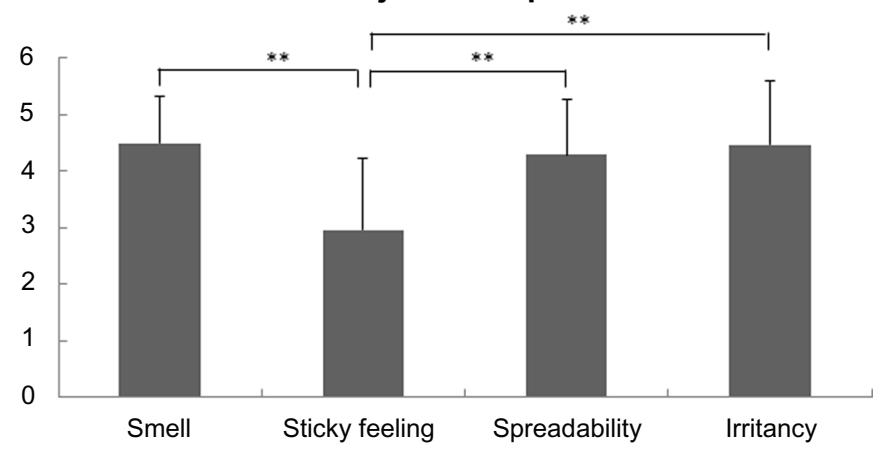

Figure 2 Estimate of priority and subjective impression in transdermal gel users. Priority (A) and subjective impression (B) in transdermal gel users were assessed as described in the "Materials and methods" section.

Notes: $* P<0.05 ; * * P<0.01$ (Steel-Dwass test). 


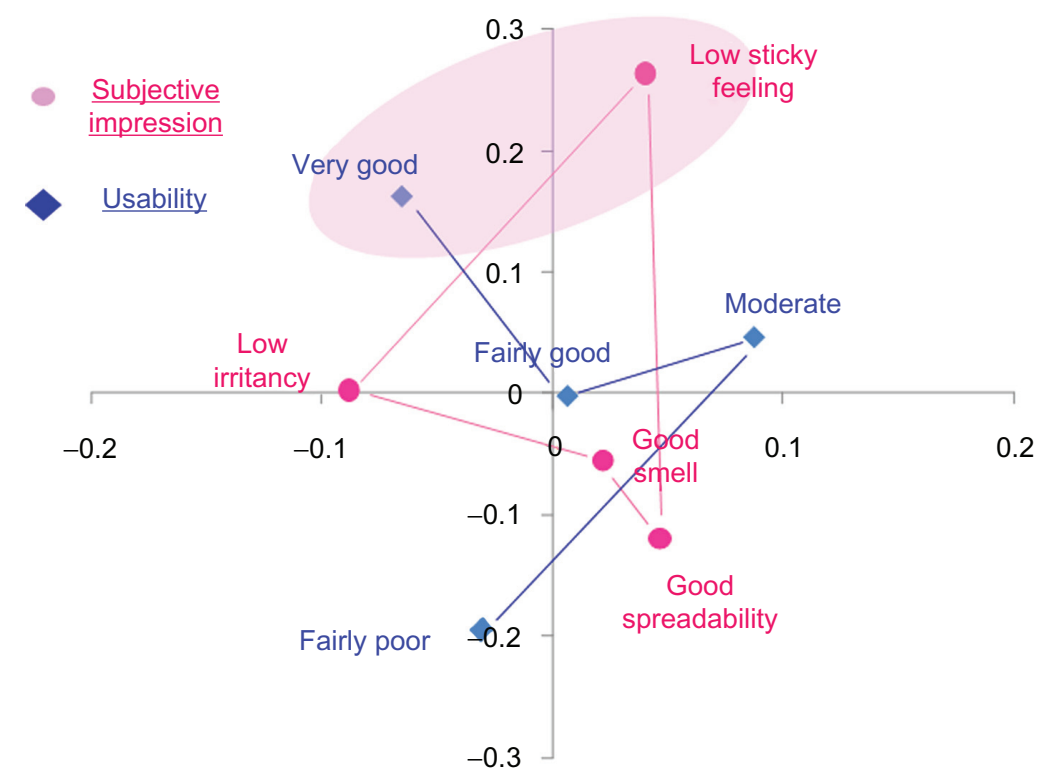

Figure 3 Correspondence analysis of the subjective impression and the usability of transdermal gel. Notes: • (closed circle): subjective impression; • (closed diamond): usability.

irritation and poor adhesion. ${ }^{9}$ The biggest disadvantage is that transdermal administration is bothersome because of its unfamiliar mode of administration. Most drugs are administered orally and the transdermal route is only used in a minority. Our data showed that there were no differences in the usability and compliance of medicines among the estrogen formulations, so the bothersome handling of transdermal administration did not seem to be a burden to HRT users. In general, women are more familiar with beauty care practices than men and our data showed that only $16 \%$ of HRT users had a low-frequency makeup habit. It is possible that most of the women could handle the transdermal formulas easily, given their similarity to cosmetics.

It has been previously reported that HRT use and the level of beauty care practices were positively associated. ${ }^{6}$ Women might expect anti-aging effects such as maintaining a youthful appearance and skin tone from HRT use. Because of its unique commonality with cosmetics, we expected that transdermal gel users might show high levels of beauty care practices. Contrary to our expectation, we could not detect a difference in beauty care practice levels between those using different estrogen formulas (Table 3 ). More than half of the women reported that they practice beauty care every day, so we speculated that we could not detect a difference because of their strong preference for makeup. We further divided the high-frequency beauty care practice group into two groups according to exercise habits (Figure 1). Exercise habits might reflect a positive mental attitude and women might expect anti-aging effects from exercise such as maintaining a youthful body and a good shape. Group 1 (high in beauty care practices, high in exercise habits) seemed to be more active than Group 2 (high in beauty care practices, low in exercise habits) in terms of their beauty care practices.

Possible avenues for future research include more detailed questions about beauty care practices such as usage of antiwrinkle cream, facial treatment, and cosmetic surgery might be useful to deepen our understanding of this issue. Concerning the compliance of patients using the different formulas, it would also be interesting to measure the plasma levels of estradiol with the use of the different formulas.

Our data suggested that "sticky feeling" is the biggest challenge for the transdermal gel formula. In Japan, we can use only one type of transdermal $17 \beta$-estradiol gel under the national health insurance system. Two newer types of transdermal estrogen formulas, transdermal spray and topical emulsion, are clear and not sticky. ${ }^{10,11}$ Introduction of these formulas to Japan would potentiate the usage of transdermal estrogen.

\section{Conclusion}

Our data suggested that the level of attention to beauty care plays some role in the choice of estrogen formulation. Transdermal gel formula was acceptable in view of the cosmetic aspects. "Sticky feeling" is the biggest challenge for the transdermal gel formula.

\section{Disclosure}

The authors report no conflicts of interest in this work. 


\section{References}

1. Cobin RH, Futterweit W, Ginzburg SB; for AACE Menopause Guidelines Revision Task Force. American Association of Clinical Endocrinologists medical guidelines for clinical practice for the diagnosis and treatment of menopause. Endocr Pract. 2006;12:315-337.

2. North American Menopause Society. Estrogen and progestogen use in peri- and postmenopausal women: July 2008 position statement of The North American Menopause Society. Menopause. 2008;15:584-602.

3. Panay N, Kalu E. Management of premature ovarian failure. Best Pract Res Clin Obstet Gynaecol. 2009;23:129-140. Epub December 16, 2008.

4. Nelson HD. Commonly used types of postmenopausal estrogen for treatment of hot flashes: scientific review. JAMA. 2004;291: 1610-1620.

5. Balfour JA, Heel RC. Transdermal estradiol. A review of its pharmacodynamic and pharmacokinetic properties, and therapeutic efficacy in the treatment of menopausal complaints. Drugs. 1990;40: 561-582.

6. Fauconnier A, Ringa V, Delanoë D, Falissard B, Bréart G. Use of hormone replacement therapy: women's representations of menopause and beauty care practices. Maturitas. 2000;35:215-228.
7. Hunter MS, O’Dea I, Britten N. Decision-making and hormone replacement therapy: a qualitative analysis. Soc Sci Med. 1997;45: 1541-1548.

8. http://www.wma.net [homepage on the Internet] World Medical Association. Declaration of Helsinki Ethical Principles for Medical Research Involving Human Subjects. [5 pages] Available from http:// www.wma.net/en/30publications/10policies/b3/17c.pdf. Accessed January 10, 2012.

9. Frenkel Y, Kopernik G, Lazer S, et al. Acceptability and skin reactions to transdermal estrogen replacement therapy in relation to climate. Maturitas. 1994;20:31-36.

10. Buster JE, Koltun WD, Pascual MLG, Day WW, Peterson C. Low-dose estradiol spray to treat vasomotor symptoms. Obstet Gynecol. 2008;111:1343-1351.

11. Simon JA. Estradiol in micellar nanoparticles: the efficacy and safety of a novel transdermal drug-delivery technology in the management of moderate to severe vasomotor symptoms. Menopause. 2006;13: $222-231$.

\section{Publish your work in this journal}

The International Journal of Women's Health is an international, peerreviewed open-access journal publishing original research, reports, reviews and commentaries on all aspects of women's healthcare including gynecology, obstetrics, and breast cancer. Subject areas include: Chronic conditions (migraine headaches, arthritis, osteoporosis);

\section{Dovepress}

Endocrine and autoimmune syndromes; Sexual and reproductive health; Psychological and psychosocial conditions. The manuscript management system is completely online and includes a very quick and fair peer-review system. Visit http://www.dovepress.com/ testimonials.php to read real quotes from published authors. 